\title{
The Forecasting Study on the Impact of Beijing- Zhangjiakou Intercity Railway on Regional Economic Development
}

\author{
Huimin Wang ${ }^{1, a}$, Jianhong $\mathrm{Wu}^{2, \mathrm{~b}}$ \\ ${ }^{1,2}$ School of Economics and Management, Beijing Jiaotong University, Beijing, China \\ a16120548@bjtu.edu.cn, bwujh@bjtu.edu.cn
}

Keywords: Beijing-Zhangjiakou Intercity Railway; Rail Transit; Regional Economy

\begin{abstract}
This paper mainly analyzes and forecasts the regional economic effects of the Beijing-Zhangjiakou intercity railway. Besides, this paper also analyzes the problems that may be faced by the Beijing-Zhangjiakou intercity railway, and puts forward some policy suggestions to promote the regional economic development.
\end{abstract}

\section{Introduction}

The innovative development of transportation not only reduces the cost of regional development, and enhances regional economic ties, but also enhances the efficiency of interregional communication. The development of high-speed rail has brought an opportunity for regional economic development and has become a research topic of concern. It is the focus of the administration of the two governments over the years that there is still a large number of impoverished counties in the area where the history is closely related(Yang Yongsheng, 2012). Therefore, in-depth study of Beijing-Zhangjiakou Intercity Railway(Referred to as Jingzhang Intercity Railway) has important value.

\section{The Influence Mechanism of Intercity Rail Transit on Regional Economic Development}

\subsection{The Impact of Construction on Regional Economic Development}

The impact of rail transit infrastructure construction on regional economic development mainly includes boosting the economic development and creating employment opportunities. Intercity rail transit is a technology and labor-intensive industry with a huge amount of investment, higher technical requirements, inclusive industry more, the construction period of the longer features, so the economic growth driven by the intercity rail transport construction is even greater. This paper uses the Keynesian theory of investment multiplier to measure the economical drawing function of investment:

$$
\Delta \mathrm{GDP}=\Delta \mathrm{I} * \mathrm{~K}
$$

where $\mathrm{K}$ is the investment multiplier and $\Delta \mathrm{I}$ is the new investment.

\subsection{Direct Impact of Rail Transit on Regional Economy}

Rail transit has greatly improved regional reachability. Compared to other existing modes of transport, the travel time along the city to other areas is greatly reduced. Thus, it also brings a time saving effect. The value-added time of high-speed railways means that travelers can increase the time to engage in other activities by reducing the travel time and thus create value.

People's activities are generally divided into productive and recreational activities. Assuming that the purpose of travel is two, that is, production and leisure activities, the time spent by passengers will also be used for production or leisure, and the probability of the two is the same. The unit time value of the production activity is measured indirectly using the unit time GDP. In economics, leisure time is also an indirect economic benefit. Because leisure time people are mainly used for rest, vacation, study and other activities, and these activities can be indirectly to improve people's work efficiency. The value of the passenger's leisure time takes $20 \%$ of the labor time value 
(Xi Kuangwu, 2004). The formula for calculating travel time savings is

$$
\mathrm{V}(\mathrm{t})=\mathrm{V}_{1}(\mathrm{t})+\mathrm{V}_{2}(\mathrm{t})=\mathrm{Q}(\mathrm{t}) \mathrm{TP}(1+20 \%)
$$

where $\mathrm{V}(\mathrm{t})$ is the benefit of travel time saving (Million yuan/ year), $\mathrm{V} 1(\mathrm{t})$ is the value created by saving time for production activities, $\mathrm{V} 2(\mathrm{t})$ is the value created by saving time for recreational activities, $\mathrm{Q}(\mathrm{t})$ is passenger traffic, $\mathrm{t}$ is year, $\mathrm{P}$-Passenger unit time value (per capita GDP), and $\mathrm{T}$ is the time saving (hours/ person).

In addition, its construction will optimize the urban structure, ease the traffic pressure, release the original railway capacity and ease the traffic problems in densely populated areas with the existing transportation network, optimize the structure between regional traffic passenger and freight transport, which is of great significance to the formation of a comprehensive regional transportation system.

\subsection{The Indirect Impact of Rail Transit on Regional Economy}

(1) Distance attenuation principle. Due to a substantial increase in driving speed, the distance between the regional nodes can not truly reflect the actual distance costs and the travel time will be greatly reduced. The relative distance shorten can accelerate the flow of various economic factors and activities between the flow, in the industrial chain division of labor and collaboration, thereby enhancing economic efficiency and cooperation in the search and use of new opportunities.

(2) Agglomeration and Diffusion Effects. As an integral part of the regional economy, transportation plays an important medium in agglomeration and diffusion. Distance is an important factor affecting agglomeration and diffusion effect, and traffic conditions will affect the distance factor, so the traffic conditions greatly affect the agglomeration and diffusion effect.

(3) Industrial development effect. High-speed railways contain a number of industries in the field of production. High-speed railway construction will promote the associated rapid development of the secondary industry. High-speed rail operations will lead to the rapid development of the tertiary industry, while some industries will also be affected by high-speed rail development.

\section{The Regional Economic Development Effect of Jingzhang Intercity Railway}

\subsection{Investment Effect of Beijing- Zhangjiakou Intercity Railway Construction}

Zhang Yan in the "Urban Rail Transit Sustainable Development Research and Engineering Demonstration" pointed out that the construction of urban rail transit can drive the growth of the national economy and demand. And according to the relevant statistical data analysis, rail transit construction projects per 100 million yuan investment can lead to GDP growth of 263 million yuan. Thus, we can get the investment multiplier $K=2.63$, then we take $K=2.63$ to measure the economic pull of JingZhang high-speed rail investment.

The total investment of the Jingzhang inter-city railway project is estimated at 58.41 billion yuan, and the total construction period is 4 years and 6 months. According to 2-1 calculate (of which $\mathrm{K}=2.63$ ), investment will stimulate economic growth of 153.6183 billion yuan.

\subsection{Jingzhang Intercity Railway Saving Travel Time to Bring the Value}

It takes 3 hours by the express train from Beijing to Zhangjiakou, expected within 1 hour after the line operating. Zhangjiakou will be included in Beijing "one hour living circle". In the above, it has been pointed out that the unit time value of production activities is measured indirectly by the unit time GDP. This paper uses the time value of production activities in Jingzhang area. 
Table 3-1 Comparison of per capita GDP along the Jingzhang intercity railway 2010-2015 (Unit: RMB)

\begin{tabular}{cccccccc}
\hline Area & 2010 & 2011 & 2012 & 2013 & 2014 & 2015 & Mean value \\
\hline Haidian District & 84474 & 93469 & 100884 & 110459 & 116639 & 124892 & \\
Changping District & 24076 & 26180 & 27667 & 29952 & 32028 & 33484 \\
Yanqing County & 21356 & 23762 & 26435 & 29209 & 31582 & 34172 & \\
Zhangjiakou & 22770 & 25793 & 28142 & 29907 & 30756 & 30840 & \\
Average & 38169 & 42301 & 45782 & 49882 & 52752 & 55847 & \\
Beijing and Hebei & 51262 & 57182 & 61838 & 66061 & 69990 & 73270 & 0.75 \\
Multiples & 0.74 & 0.74 & 0.74 & 0.76 & 0.75 & 0.76 & 0.07 \\
Growth rate & & 0.12 & 0.08 & 0.07 & 0.06 & 0.05 & 0.07 \\
\hline
\end{tabular}

The table shows the per capita GDP growth rate is 0.07 in Beijing and Hebei from 2010 to 2015 . We take 2015 the per capita GDP in Beijing and Hebei as the base and 0.07 as the basic average growth rate. From the above table, we can calculate that the per capita GDP is 0.75 times of the average level of Beijing and Hebei along the Jingzhang region. Accordingly, we can measure per capita GDP along the region. Working time in accordance with the annual work is 50 weeks, with 40 hours a week, so working time is 2000 hours a year. As in the table below, we calculate the unit production time value along Jingzhang intercity railway.

Table 3-2 The unit production time value in the areas along the Jingzhang area between 2015 and 2030

\begin{tabular}{cccccccc}
\hline Year & $\begin{array}{c}\text { Per } \\
\text { capita } \\
\text { GDP } \\
\text { (Yuan) }\end{array}$ & $\begin{array}{c}\text { Per capita } \\
\text { GDP } \\
\text { (Yuan) }\end{array}$ & $\begin{array}{c}\text { The unit production } \\
\text { time value (yuan/ } \\
\text { hour) }\end{array}$ & Year & $\begin{array}{c}\text { Per capita } \\
\text { GDP } \\
\text { (Yuan) }\end{array}$ & $\begin{array}{c}\text { Per capita } \\
\text { GDP } \\
\text { (Yuan) }\end{array}$ & $\begin{array}{c}\text { The unit } \\
\text { production time } \\
\text { value (yuan/ hour) }\end{array}$ \\
\hline 2015 & 73270 & 55847 & 27.92 & 2023 & 125891 & 94418 & 47.21 \\
2016 & 78398 & 58799 & 29.40 & 2024 & 134703 & 101027 & 50.51 \\
2017 & 83886 & 62915 & 31.46 & 2025 & 144132 & 108099 & 54.05 \\
2018 & 89758 & 67319 & 33.66 & 2026 & 154221 & 115666 & 57.83 \\
2019 & 96041 & 72031 & 36.02 & 2027 & 165017 & 123763 & 61.88 \\
2020 & 102764 & 77073 & 38.54 & 2028 & 176568 & 132426 & 66.21 \\
2021 & 109958 & 82468 & 41.23 & 2029 & 188928 & 141696 & 70.85 \\
2022 & 117655 & 88241 & 44.12 & 2030 & 202153 & 151615 & 75.81 \\
\hline
\end{tabular}

At present, it takes 2 hours at least from Zhangjiakou to Beijing. Jingzhang intercity railway will be completed by the end of 2019 , with the total length of $174 \mathrm{~km}$, according to $250 \mathrm{~km} / \mathrm{h}$ operation Zhangjiakou to Beijing only takes 42 minutes. Assuming not considering other factors, each passenger can save 1.3 hours of travel time. The Jingzhang intercity passenger capacity is up to 60 million people, where we take $80 \%$ of the attendance rate of the traffic as the estimated annual value of the average passenger traffic, which is 48 million people.

According to the formula (2-2), we bring the above data into the formula to calculate the value of the time savings from the Jingzhang intercity railway. According to the progress of the project, it will be opened at the end of 2019, so we estimate the data from 2020 to 2030. It can be seen from the calculation results in Table 3-3 that the value of saving time brought by Jingzhang intercity railway is huge.

Table 3-3 The value of Beijing-Zhang Intercity Railway saving time along the region between 2020 and 2030

\begin{tabular}{lccccc}
\hline Year & $\begin{array}{c}\text { The unit production } \\
\text { time value (yuan/ } \\
\text { hour) }\end{array}$ & $\begin{array}{c}\text { The total value of time } \\
\text { saving (ten thousand yuan) }\end{array}$ & Year & $\begin{array}{c}\text { The unit } \\
\text { production time } \\
\text { value (yuan/ hour) }\end{array}$ & $\begin{array}{c}\text { The total value of } \\
\text { time saving (ten } \\
\text { thousand yuan) }\end{array}$ \\
\hline 2020 & 38.54 & 144281.03 & 2026 & 57.83 & 216526.92 \\
2021 & 41.23 & 154380.70 & 2027 & 61.88 & 231683.80 \\
2022 & 44.12 & 165187.35 & 2028 & 66.21 & 247901.67 \\
2023 & 47.21 & 176750.46 & 2029 & 70.85 & 265254.78 \\
2024 & 50.51 & 189122.99 & 2030 & 75.81 & 283822.62 \\
2025 & 54.05 & 202361.60 & & & \\
\hline
\end{tabular}




\subsection{Jingzhang Intercity Railway on the Role of Regional Industrial Development}

In 2016, in Zhangjiakou, the proportion of three industries is 18:37:45. The city's secondary industry is lower than the province's 10.1 percentage points. With the national average compared to 2.6 percentage points worse, the proportion of the secondary industry was significantly lower. The proportion of tertiary industry is higher than the 2.9 percentage points in Hebei, which is relatively low proportion of secondary production. The city's tertiary industry development structure is not excellent, and the traditional service industry is still dominant in the tertiary industry. At present, the development of the industry has a certain foundation; the regional division of labor is being formed; industrial layout is not enough degree along the line; the industry is not closely related. Overall, the industrial structure is not reasonable, but the construction of line is conducive to improving the development of the tertiary industry along the region. It is also main the passenger transport, which will release the original line freight capacity, so as to improve the freight capacity of the original line (Wang Jing, 2010), is conducive to reducing the cost of freight companies, and is conducive to the development of the logistics industry. And it will also attract other traffic routes, and greatly release the original area of the potential passenger flow, and attract passenger traffic to increase the number of tourists and tourism revenue, bringing a great role in promoting the region's tourism industry (Zhang Yun, Wu Yiqing and Tao Jingjing, 2013).It is also conducive to Zhangjiakou area to seize the opportunity of industrial transfer, and form a number of scale and level of the forefront of the advanced manufacturing and high-tech industry cluster.

\section{The Problems Faced by the Jingzhang Area}

Jingzhang inter-city railway is both an opportunity and a challenge. The effect of Intercity high-speed rail on the regional economic development has close contact with the regional policy-oriented, regional economy and other supporting transport facilities along the line. While the area along the city of Beijing is facing inadequate development of traffic, backward traffic constraints economic development, lack of economic development capacity, intercity high-speed rail may increase the abnormal development of the economy.

\section{Policy Suggestions for Promoting Regional Development along the Line}

Speeding up the construction of intercity railway and improving the regional transport network; Perfecting the construction of integrated traffic hub in Jingzhang Railway Station and enhancing the radiation-driving role of transportation hub; speeding up the development of small towns along the line, and guiding the cooperation and the development of special industries along the line through the policy (Zhang Yaming, Yang Lisa and Tang Zhaosheng, 2012).

\section{References}

[1] Sun Cuilan and Franco, Base Yu " point-axis model" Rail traffic construction and development of regional economy, Shanxi railway engineering vocational and technical college, vol. 9, pp. 47-48, 2011.

[2] Wang Jing, Overall development goals establish around Beijing capital economic circle, central city " Twelve-Five " Planning, logistics technology, vol. Z2, pp. 13, 2010.

[3] Xi Kuanwu, Cangzhou section of the Beijing-Shanghai Expressway on regional socio-economic impacts, Journal of Beijing University of technology, vol. 30, pp. 95, 2004.

[4] Yang Yongsheng, Some thoughts on the development of poor areas of the city, Zhangjiakou daily, vol. 15, pp. 32, 2012. 
[5] Zhang Yun, Wu Yiqing and Tao Jingjing, Central Beijing eco-economic zone concept --Building beautiful Metropolitan strategic initiatives, Research and development, vol. 3, pp. 5-7, 2013. 